\title{
Fatal intoxications among non-drug addicts in Eastern Denmark over a 5-year period (2008-20I2)
}

This article was published in the following Dove Press journal: Research and Reports in Forensic Medical Science

\section{Sys Stybe Johansen Christina Jacobsen ${ }^{2}$ Kristian Linnet'}

'Section of Forensic Chemistry, Department of Forensic Medicine, Faculty of Health and Medical Sciences, University of Copenhagen, Copenhagen, Denmark; ${ }^{2}$ Section of Forensic Pathology, Department of Forensic Medicine, Faculty of Health and Medical Sciences, University of Copenhagen, Copenhagen, Denmark
Correspondence: Sys Stybe Johansen Section of Forensic Chemistry, Department of Forensic Medicine, University of Copenhagen, Frederik Femtes Vej II, DK-2 I00 Copenhagen OE, Denmark

Tel +453532624 I

Fax +4535326085

Email sys.johansen@sund.ku.dk
Purpose: We present a retrospective analysis of fatal intoxications among non-drug addicts medicolegally autopsied in Eastern Denmark (DK) over a 5-year period (2008-2012) and compare our results with three older similar studies covering periods from 1992 to 2007.

Material and methods: Retrospective results showed that among 3,535 medicolegal autopsies performed in Eastern DK within the 5-year study period, 312 were fatal intoxications among non-drug addicts.

Results: A total of $67 \%$ of the intoxications were caused by pharmaceuticals, most often by strong opioids, $23 \%$ by carbon monoxide in connection with fires and $9 \%$ by acute ethanol intoxication. The number of fatal intoxications varied within the 5-year period from 52 to 75 per year. A total of $54 \%$ of the intoxications involved men, and the dominant age groups were 40-49 years for men and 50-59 years for women. In 57\% of the fatal intoxications, the manner of death was accidental; $24 \%$ were suicides; $0.6 \%$ were homicides; and $16 \%$ were unknown. A total of $75 \%$ of the intoxications involved one substance, $11 \%$ involved multiple substances (all at lethal post-mortem blood concentrations), and 13.5\% were combination intoxications. Although the total number of intoxications had decreased by $25 \%$ from the previous 5-year period, carbon monoxide, ethanol, and the strong opioids morphine and methadone were again the most common fatal substances. Tramadol, another opioid, was the fifth most fatal intoxicating substance, and its prevalence increased within the last two study periods, as also seen in the amount of defined daily doses of tramadol sold in DK. Clozapine, an antipsychotic drug, was new among the ten most fatal intoxicating substances in this study.

Conclusion: In general, the findings are comparable with the last 20 years' observations in DK, although the number of intoxications was reduced by $25 \%$. Small changes among the most frequent fatal substances were observed compared with the previous periods.

Keywords: fatal poisonings, cause of manner and death, medicine users, ethanol, pharmaceuticals, DDDs

\section{Introduction}

In toxicological analyses of fatal intoxications, the main focus is typically on illegal drugs and new psychoactive substances among drug addicts. However, it is also relevant to record the general population's consumption of pharmaceuticals and other chemicals, including the consequences of this consumption. Indeed, such studies are rare and often have a limited drug perspective or cover all fatal intoxications, including drug addicts, which, therefore, dominate the picture completely as observed in previous studies. ${ }^{1-3}$ An overview of all forensic toxicological investigations performed on samples from autopsies is important to identify patterns and changes of applied drugs 
and may result in warnings of hazards associated with drugs in use. By dividing the forensic results in groups of drug addicts and non-drug addicts, it is possible to study the latter group more thoroughly as it is a much smaller group. This group size difference is due to the Danish law that only requires drug addict cases to be subjected to medicolegal autopsy and toxicological investigation. ${ }^{4}$ The study period, therefore, needs to be extended to several years to be able to follow the pattern and changes of applied pharmaceuticals among the non-drug addicts in Eastern Denmark (DK). ${ }^{3}$ Misuse/abuse of pharmaceuticals can also be estimated from sales data; however, following the forensic toxicological evaluations over a period of time can provide a supplementary hazard assessment and documentation for implementing drug regulation. Especially, if regular comparison of similar studies is done, it is then possible to identify changes in applied drugs and misuse of hazard substances among non-drug addicts. To the authors' knowledge, the division between addicts and non-drug addicts among medicolegal autopsies is relatively seldom, and we can, therefore, not compare the results with many other similar international studies. Furthermore, we have recognized that by evaluating all the medicolegal material, the low amount of fatal intoxications among non-drug addicts tends to vanish. ${ }^{2,3}$ Also, there are significant differences between countries, even between neighboring countries. An example was demonstrated in the Nordic comparison of fatal intoxications among drug addicts, where the fatal drug distribution of heroin/morphine, methadone, buprenorphine, and other opioids is very different between the four Nordic countries mainly due to the differences in treatment programs. ${ }^{4}$ The aim of this study was, therefore, to determine the drugs involved in fatal intoxications among non-drug addicts in Eastern DK over a 5-year period (2008-2012) and evaluate these against former comparable studies ${ }^{3,5,6}$ and against the sales statistics for medicinal drugs within the period. The identified changes in drugs involved in the fatal intoxications among non-drug addicts were then compared with the international literature.

\section{Materials and methods}

This study includes results from medicolegal autopsies at the Department of Forensic Medicine, University of Copenhagen, performed from 2008 to 2012 . In DK, medicolegal autopsies are requested by the police after a medicolegal external inquest. The department performs these investigations for Eastern DK (Zealand, surrounding islands, and Bornholm), which represented a population of about 2.5 million people during those 5 years. ${ }^{7}$ In the period 2008-2012, 122,925 people died in Eastern DK, ${ }^{8}$ and of these, 3,535 medicolegal autopsies were performed (2.9\%). Forensic toxicological investigations were requested in 1,779 of the medicolegal autopsies $(50 \%)$. The forensic toxicological investigations are conducted in cases with suspicion of intoxications and/or uncertainty about or lack of cause of death based on the autopsy. Drug addicts were excluded and defined as persons who, according to case information, were known or observed to have abused drugs intravenously and/or abused drugs listed in the Single Convention on Narcotic Drugs 1961, Schedule I and/or the International Convention on Psychotropic Substances 1971, Schedules I and II. ${ }^{4,5}$ This means that results of former drug addicts are not included here but are reported elsewhere. ${ }^{4}$

The toxicological investigations were performed on femoral blood in the majority of the cases, while in a few cases, muscle tissue samples were used. Screenings for drugs and relevant metabolites were performed by chromatographic methods, such as liquid chromatography (LC) coupled to time of flight mass spectrometry and by multi-target LC tandem mass spectrometry methods (LC-MS/MS) in order to cover as many drugs as possible. ${ }^{9-13}$ Positive drug results were confirmed and quantified by an alternative analytical method, typically an LC-MS/MS method. ${ }^{10-13}$ Most cases were investigated for multiple drugs, both legal and illegal, and poisons, but in a few cases only, a specific analysis, such as ethanol or carbon monoxide, was requested due to strong suspicion toward these substances. The manner of death is based on the final forensic pathology report where the case circumstances have been taken into account. In a number of cases, the case circumstances are not conclusive, and these cases were labeled "unknown manner of death". Accident refers to the assumption that a presumed overdose was not intended as in a suicide but rather it represents an overdose, often a combination of drugs, in order to achieve an (exaggerated) euphoriant effect. In suspected suicide cases in $\mathrm{DK}$, a medicolegal autopsy is only requested by the police when there is doubt about the cause or manner of death. Additionally, cases where the combination of several drugs in non-lethal concentrations was considered lethal (combination intoxications) are included in this study. Alcoholic ketoacidosis fatalities were not included in this study.

This is a retrospective investigation of the routine forensic results collected over a defined period for quality control purposes. The data handling has been done in the laboratory's routine IT-system, which is secure (not coupled to the Internet) with logging of access, which complies with Danish Data-ethics rules. The study does not involve human biological samples, and the presented results are non-identifiable data, and so complies with the Helsinki Declaration. Approval 
from the Danish Ethics committee for Medical Research is not relevant in this investigation, neither informed consent from relatives.

\section{Results}

Of the 1,779 medicolegal autopsies where toxicological investigations were performed during the 5-year study period from 2008 to 2012, 1,092 cases were considered non-drug addicts, and of these, 312 deaths were due to fatal intoxication. The annual number of intoxications among non-drug addicts was 61 in 2008, 57 in 2009, 67 in 2010, 75 in 2011, and 52 in 2012, an average of 62 intoxications per year. The cases involved 144 females (46\%) and 168 males (54\%) as shown more thoroughly in Figure 1. The highest numbers were observed for men aged 40-49 years $(n=46)$ and women aged $50-59$ years $(n=37)$. A total of $90 \%$ of the fatal intoxication cases represented an age distribution from 30 to 79 years.

The manner of death in the 312 fatal intoxications was presumed to be accidental $(57.4 \% ; n=179)$, suicides $(24.4 \%$; $\mathrm{n}=76)$, homicides $(0.6 \% ; n=2)$, or unknown $(16.0 \% ; n=50)$. In $1.6 \%$ of the cases $(n=5)$, the manner of death was assessed as being natural even though the drug concentration was elevated.

In 42 cases (13.5\%), no substances were found at a lethal concentration, but the combination of drugs was considered fatal. In the remaining 270 cases, one or more substances were observed at a lethal concentration. Among these, a single substance at a lethal concentration was observed in 235 cases $(75 \%)$, while multiple substances at lethal concentra- tions were observed in 35 cases (11\%). In these 35 multiple intoxication cases, 80 different drugs were involved, with an average of 2.3 involved substances per case. The multiple intoxications involved in $>50 \%$ of these cases were codeine $(n=7)$, morphine $(n=6)$, salicylic acid $(n=3)$, and tramadol $(n=2)$.

In the fatal intoxications with one or more substances at a lethal concentration, $67 \%$ involved pharmaceuticals; $9 \%$ of the deaths were caused by acute ethanol intoxication and $23 \%$ by carbon monoxide and/or cyanide. The latter were all fire-related deaths and, therefore, cyanide was included in these cases. The pharmaceuticals involved in fatal intoxications were divided according to therapeutic use (Figure 2 ), demonstrating that the most dominant group was that of strong opioids at $34 \%$, and the second group was of weak opioids at $17 \%$.

In total, 42 different substances were involved in the 270 fatal intoxications among single and multiple drug intoxications. The most frequent substance involved in the fatal intoxications among non-drug addicts was carbon monoxide with 73 cases $(27 \%)$, the manner of death being accidental in $85 \%$ of these cases, as shown in Table 1 . A list of the most frequent fatal substances is given in Table 1 along with the distribution of manner of death.

The second and third most frequent fatal substances were ethanol and morphine, both at $10 \%$, while methadone was the fourth most frequent. These four substances constituted over half of the fatal intoxications (51\%). Ethanol contributed to the death in 31 of the 312 non-addicts' fatal intoxications $(9.7 \%)$ and was involved in 16 of the combination intoxications. The

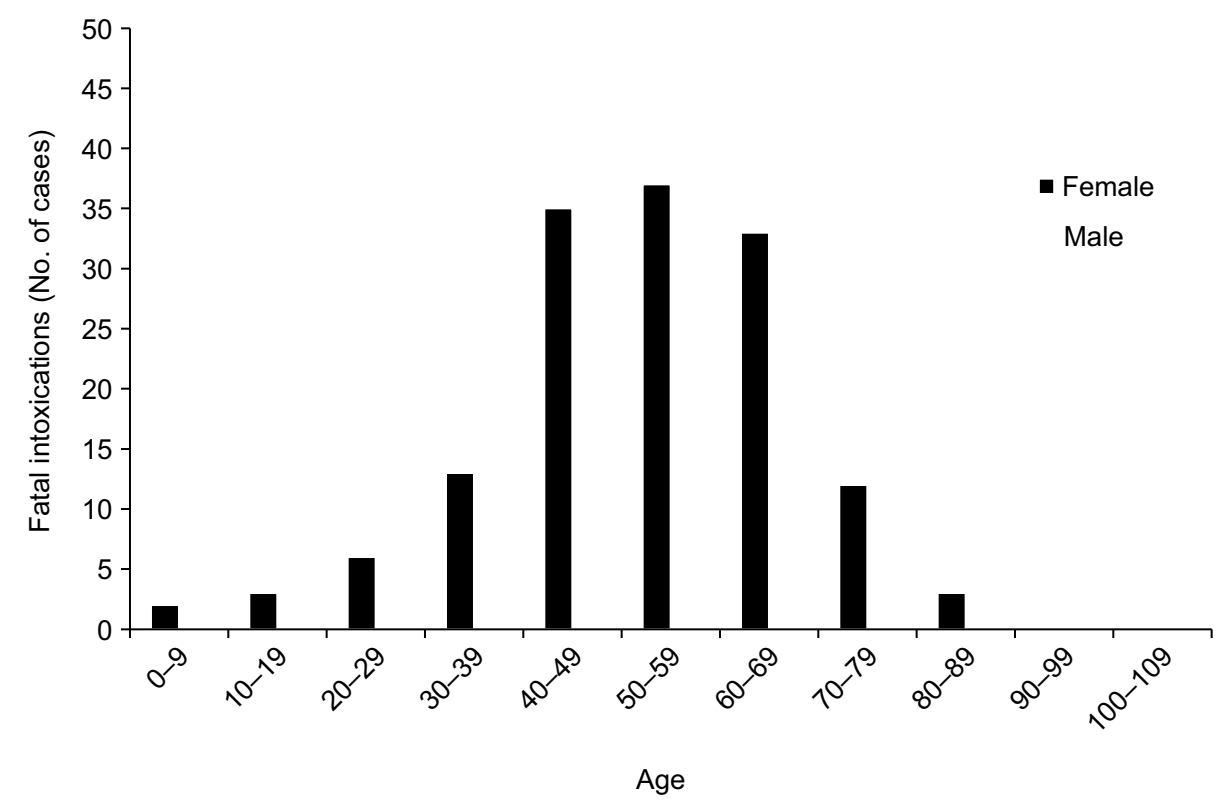

Figure I Age (years) and sex distribution of the 312 fatal intoxications among non-addicts in Eastern Denmark from 2008 to 2012. 


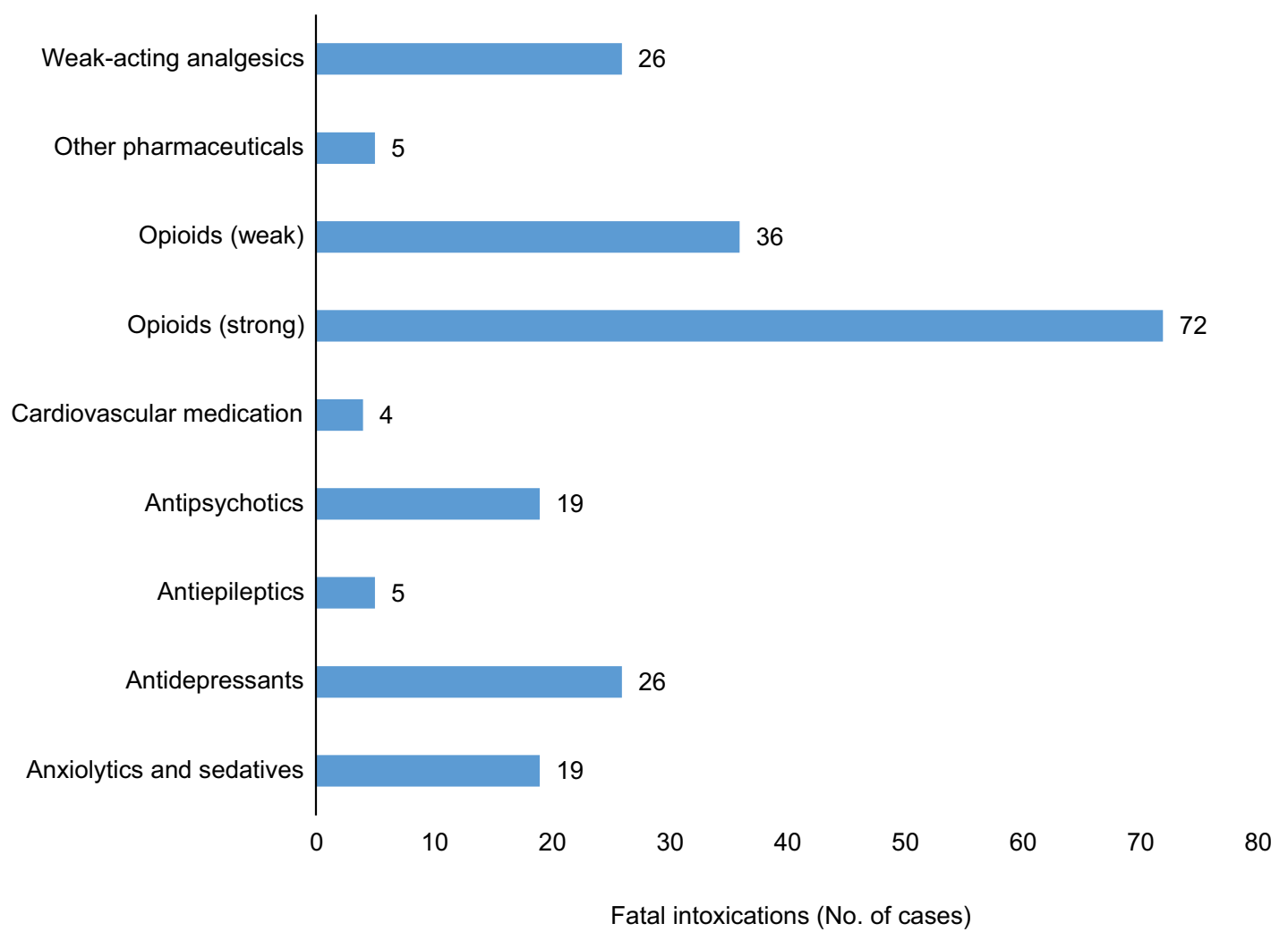

Figure 2 Distribution of pharmaceutical indication-groups associated with fatal intoxications among non-drug addicts in Eastern Denmark.

Notes: Please note that the number of observations in the figure does not correlate directly with the total number of cases because a case with more than one toxic substance at a lethal level was included once for each fatal drug. Typical strong opioids were methadone and morphine; weak opioids were codeine and tramadol; weakacting analgesics were paracetamol and salicylic acid; antipsychotics were, eg, chlorprothixene and clozapine; and antidepressants were, eg, ami-/nortriptyline and venlafaxine. Amitriptyline and nortriptyline were regarded together as nortriptyline, which is an active metabolite of amitriptyline as well as an individual antidepressant. Anxiolytics and sedative drugs were typically alprazolam and zopiclone; antiepileptics were phenobarbital and gabapentin; cardiovascular drugs typically meant propranolol; and other pharmaceuticals $(n=5)$ were dipyridamole, flecainide, ketamine, methylphenidate, and terbutaline.

majority of acute ethanol intoxications were accidental (77\%), while fatal intoxications with the two strong opioids, morphine and methadone, were involved in either accidents or suicides, although for methadone, the last half were either suicides $(22 \%)$ or an unknown manner of death (19\%) (see Table 1).

In this study period, two cases were homicides, both involving intoxications with carbon monoxide from a lit grill in a sealed room.

The major groups of pharmaceuticals involved in combination intoxications were, in prioritized order, anxiolytics, antipsychotics, antidepressants, and strong opioids along with ethanol. Typically, the manner of death was either accidental $(47 \%)$ or unknown (35\%); less often, it was suicide (16\%). Suicides often involved multiple drug intoxications, typically codeine, salicylic acid, and morphine. Codeine and salicylic acid are the ingredients of Kodimagnyl ${ }^{\circledR}$ Ikke stoppende "DAK", Takeda Pharma A/S, Taastrup, Denmark, while morphine could be due to biodegradation of codeine.

Among the most frequent intoxicating substances, it was not possible to determine any yearly trend within the 5-year period as the numbers each year were generally too small; however, an increasing trend was present for morphine and tramadol from 2008 to 2012, while ethanol decreased somewhat.

\section{Discussion}

In general, the results are very similar to the previous period (2003-2007). ${ }^{5}$ An issue to note is the $25 \%$ decrease in the total number of fatal intoxications among non-drug addicts from 428 cases in the previous period to 312 in the present period. The decline in the total number of medicolegal autopsies only changed by $8 \%$, from 3,847 to 3,535 . Even so, the male-female proportion of occurrences was the same and the distributions of combination, single or multiple intoxications, and the manner of death were also similar. The combination intoxications increased by $2.5 \%$ while single intoxications fell accordingly. Suicides increased by $4 \%$, and unknown manner of death decreased accordingly. The percentage of accidents remained roughly the same. In this period, 42 different substances were involved in the single and multiple intoxications, while it was 57 in the last period. These reductions may be the results of better selections and controls with drug intake and regular performances of medicine reviews in the public health 
Table I The 23 most frequent intoxicating substances in lethal concentrations among non-drug addicts in Eastern Denmark from 2008 to 2012 with specifications of manner of death

\begin{tabular}{|c|c|c|c|c|c|c|c|}
\hline & & Cases (n) & Manner of death & & & & \\
\hline No. & Substance & $2008-2012$ & Accident (\%) & Suicide (\%) & Homicide (\%) & Natural (\%) & Unknown (\%) \\
\hline 1 & Carbon monoxide & 73 & 84.9 & 6.8 & 2.7 & & 5.5 \\
\hline 2 & Ethanol & 31 & 77.4 & 3.2 & & & 19.4 \\
\hline 3 & Morphine & 30 & 46.7 & 46.7 & & & 6.7 \\
\hline 4 & Methadone & 27 & 55.6 & 22.2 & & 3.7 & 18.5 \\
\hline 5 & Tramadol & 18 & 27.8 & 44.4 & & 11.1 & 16.7 \\
\hline 6 & Ami-/nortriptyline & 17 & 50.0 & 44.4 & & & 5.6 \\
\hline 7 & Codeine & 17 & 41.2 & 52.9 & & & 5.9 \\
\hline 8 & Paracetamol & 13 & 53.8 & 15.4 & & & 30.8 \\
\hline 9 & Salicylic acid* & 13 & 23.1 & 38.5 & & & 38.5 \\
\hline 10 & Clozapine & 7 & 28.6 & 71.4 & & & \\
\hline II & Oxycodone & 7 & 28.6 & 57.1 & & & 14.3 \\
\hline 12 & Venlafaxine & 7 & 57.1 & 42.9 & & & \\
\hline 13 & Ketobemidone & 6 & 33.3 & 50.0 & & & 16.7 \\
\hline 14 & Chlorprothixene & 5 & 40.0 & 40.0 & & & 20.0 \\
\hline 15 & Fluoxetine & 4 & 50.0 & 25.0 & & & 25.0 \\
\hline 16 & Propranolol & 4 & 25.0 & 50.0 & & & 25.0 \\
\hline 17 & Phenobarbital & 3 & 33.3 & 33.3 & & & 33.3 \\
\hline 18 & Quetiapine & 3 & 33.3 & 33.3 & & & 33.3 \\
\hline 19 & Zopiclone & 3 & 66.7 & 33.3 & & & \\
\hline 20 & Alprazolam & 2 & & 100.0 & & & \\
\hline 21 & Citalopram & 2 & 50.0 & 50.0 & & & \\
\hline 22 & Fentanyl & 2 & 50.0 & 50.0 & & & \\
\hline 23 & Olanzapine & 2 & 100.0 & & & & \\
\hline
\end{tabular}

Notes: Intoxicating substances with only one death within the 5 -year period are omitted here. *Salicylic acid can be a metabolite of acetylsalicylic acid and is the target in the chemical analysis.

system. However, many other parameters may exert influence, such as the selection of cases by the police for medicolegal autopsies, which are only performed if there is doubt about the manner and/or cause of death. The request of toxicological investigations were reduced from $69 \%$ to $50 \%$ of the medicolegal autopsies from the previous period to this period. Also, the police request of a limited toxicology report in cases with a strong suspicion of the cause of death, for example, carbon monoxide in fire-related death and ethanol among alcoholics may influence the results. Table 2 provides an overview of the ten most common intoxicating substances for this and earlier periods since 1992. The oldest study (1992-1996) chose only to count the most substantial substance in multiple intoxications. ${ }^{3}$ This may affect the ranking and also the number of cases of each intoxicating drug, which is why the numbers are lacking for this period in Table 2.

The occurrence of carbon monoxide/cyanide increased from $18.5 \%$ in the previous period to $23 \%$ of the intoxications. Most of these intoxications were in connection with fires, where a competing cause of death could have been extensive burns. Peiris-John et al ${ }^{14}$ observed that carbon monoxide was involved in most fatal intentional selfpoisoning incidents, which the homicides in this study might also suggest. They also observed that pharmaceuticals were the main substance in fatal unintentional poisonings and poisoning admissions, which our results also partly suggest (Table 1).

Ethanol intoxications were almost halved from the previous study, from 58 to 31 cases (Table 2), which probably explains some of the decrease in fatal intoxications. However, ethanol was still the second most frequent fatal intoxicant. Ethanol was also among the most prevalent substance in single-drug fatalities in a Swedish study,${ }^{15}$ and as ethanol is not regulated as pharmaceuticals are, this is a well-known issue that probably will continue.

The frequency with which the various drugs were involved in fatal intoxications was compared with the changes in the amount of defined daily doses (DDDs) sold in Eastern DK of each pharmaceutical that was present in a high number. Morphine was stable in the beginning of the period at 4.3-4.8 DDD until 2010, when it increased to 6.4 DDD within the 5 years. ${ }^{16}$ In the present period, morphine ranked higher (number 2), although the total number of morphine intoxications dropped a little, from 33 to 30 , and the percentage increased from $7.7 \%$ to $9.3 \%$. The longer-acting opioid, methadone, was stable at $13-13.9 \mathrm{DDD}^{16}$ within the period, though the 


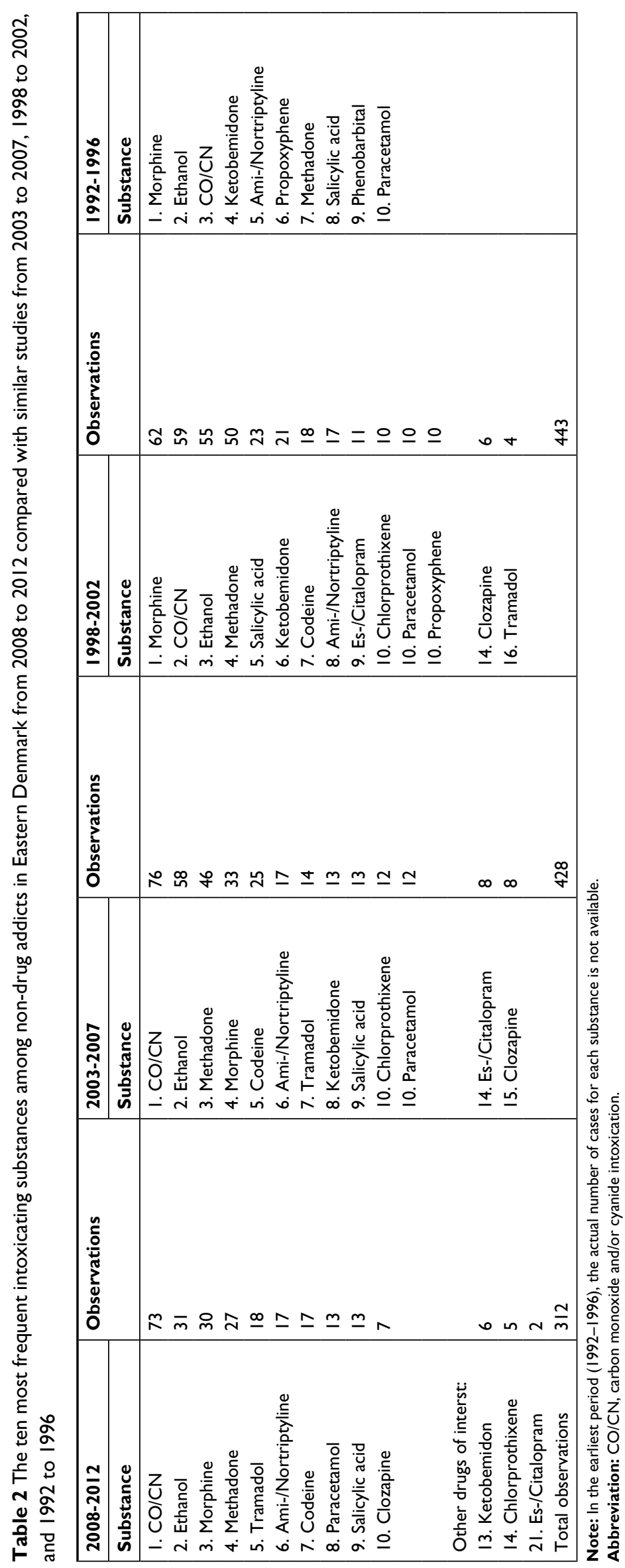


percentage of intoxications fell from $10.7 \%$ to $8.4 \%$. In general, methadone prescriptions for pain management should be limited as safer drug alternatives are available. ${ }^{17}$

Tramadol is a weak opioid analgesic with effects similar to codeine. Tramadol steadily increased from 16 to 18.9 DDD (18\% increase) in the 5-year period, and the intoxications increased from $3.3 \%$ to $5.8 \%$, while codeine mixed with weak-acting analgesics fell from 18.2 to 13.5 in DDD but contributed to $5 \%$ of the intoxications in both periods. The Swedish study evaluating 13,963 fatal intoxications among drug addicts and non-drug addicts from 1993 to 2010 found tramadol among the ten most prevalent drugs in fatal singledrug intoxications (20 cases), and tramadol was also involved in 713 fatal multiple-drug intoxications..$^{15}$ A $10 \%$ increase in tramadol deaths from 1996 to 2012 was also observed in Northern Ireland according to Randall and Crane. ${ }^{18}$ In that study, 53\% were considered abusers since the drug had not been prescribed by a medical practitioner. The deceased in our cases had not been classified as drug addicts according to our guidelines. Even though drug addiction might have been suspected, the deceased did not have any history of drug abuse or any illegal drug finding. Unfortunately, we did not have access to prescribed or collected medicine for our cases.

Fatal intoxication cases with weak painkillers, such as salicylic acid and paracetamol, were roughly unchanged compared with the previous period, which was also the case for the DDDs.

DDDs of both amitriptyline and nortriptyline increased to some extent from 3.6 to 3.8 and from 1.8 to 2.4 , respectively. The number of intoxications was 17 in both the previous and actual periods, but the percentage was higher now (5.4\%) compared with the last period (4\%). These tricyclic antidepressants are known to be cardiotoxic, and newer, less toxic antidepressants are available. Some of the newer antidepressants were also among the list of fatally intoxicating drugs, as venlafaxine is the 12th with seven cases, fluoxetine the 15th with four cases, and (es-)/citalopram the 21st with two cases within the 5-year period. (Es-)Citalopram was 9th on the list of most frequently intoxicating substances in the period 1998-2002, but it fell to 14th in 2003-2007 and dropped even more to $21 \mathrm{st}$ in this study. Thus, the total DDD of (es-)/citalopram first increased from 66.9 to 73.1 until 2010 and then decreased to 62 within this 5 -year period, but citalopram increased a little from 45.9 to 50.9, while escitalopram halved from 21 to 11.1. In comparison, amitriptyline and citalopram were among the ten most prevalent drugs, with 32 and 28 single-drug intoxications, respectively, in the Swedish study. ${ }^{15}$
A new pharmaceutical, clozapine, a second-generation antipsychotic drug, was among the most frequent intoxicating substances observed in this study. It was the tenth most frequent drug, with seven cases (2.1\%), while in the last study, ${ }^{5}$ it was number 15 with eight cases (1.9\%), and in the period before then, from 1998 to 2002, it was number 14 with six cases $(1.4 \%){ }^{6}$ In this period, the DDD of clozapine was stable at 1.5-1.6. Among the applied antipsychotics in DK, clozapine is known as less toxic compared with first-generation antipsychotics, such as chlorprothixene. A group in Finland evaluated the fatal toxicity index of medicinal drugs based on a comprehensive toxicology database and found clozapine the least toxic among regularly used antipsychotics, such as chlorprothixene and quetiapine. ${ }^{19}$

Comparison of the new list of intoxicating substances with the previous lists also showed a decrease for chlorprothixene and ketobemidone intoxications from 10th to 14th and 8th to 13th in frequency, respectively. Chlorprothixene dropped from 12 cases in the previous period to 5 $(2.8 \%-1.6 \%)$, while the opioid ketobemidone decreased from 13 cases to $6(3 \%-1.8 \%)$. Some decreases were also observed for the DDD data, as these went from 1.4 to 1.2 for chlorprothixene and 2.5 to 1.6 for ketobemidone (Ketogan ${ }^{\circledR}$, Pzifer ApS, Ballerup, Denmark). These decreases were expected as prescription interventions have been made and drug alternatives with fewer side effects and better safety are available in the Danish market.

\section{Conclusion}

By results from toxicological investigations of non-drug addicts in the study period from 2008 to 2012, the cause of death was identified for $29 \%$ as fatal intoxications. In general, many similarities to the previous period's characteristics were observed, for example, a male-female ratio of $1: 1$ and the distribution between single, multiple, and combination intoxications. However, request of toxicological investigations of medicolegal autopsies was reduced by $19 \%$ from previous period, and also the amount of fatal intoxications among non-drug addicts decreased considerably, $25 \%$ since the previously recorded period (2003-2007), especially with regard to acute ethanol intoxications. The major substances involved in fatal intoxications among non-drug addicts are still carbon monoxide, ethanol, morphine, and methadone. Some drugs were new among the most frequently intoxicating substances, for example, clozapine and tramadol. Doctors and the public need to become aware of the high occurrence of tramadol intoxications. Some correlation between drug findings, now and in the previous period, and the sales data 
of pharmaceuticals was observed. Regulation and restrictions concerning prescriptions of opioids are still highly relevant.

\section{Acknowledgment}

Thanks to Steen Madsen for help with the case selection.

\section{Disclosure}

The authors report no conflicts of interest in this work.

\section{References}

1. Cerdá M, Ransome Y, Keyes KM, et al. Prescription opioid mortality trends in New York City, 1990-2006: examining the emergence of an epidemic. Drug Alcohol Depend. 2013;132(1-2):53-62.

2. Worm K, Steentoft A. Death from poisoning in East Denmark 19841991. Ugeskr Lager. 1994;156(20):3039-3043.

3. Worm K, Steentoft A, Toft J. Deaths due to poisoning during a five-year period in East Denmark (1992-1996). Ugeskr Laeger. 1999;161:6622-6625.

4. Simonsen KW, Edvardsen HM, Thelander G, et al. Fatal poisoning in drug addicts in the Nordic countries in 2012. Forensic Sci Int. 2015;248:172-180.

5. Petersen JH, Johansen SS, Haugerid C. Fatal intoxications among nondrug addicts in Eastern Denmark over a five-year period (2003-2007). Res Rep Forensic Med Sci. 2012;2:1-7.

6. Johansen SS, Jacobsen C, Müller IB, et al. [Poisoning deaths over five years (1998-2002) in Eastern Denmark]. Forgiftningsdødsfald over en femårig periode (1998-2002) i Østdanmark. Ugeskr Laeger. 2006;168:3326-3331. Danish [with English abstract].

7. Statistics Denmark. Population FOLK1A (2008-2012). Available from: http://www.statistikbanken.dk/statbank5a/default.asp?w=1366. Accessed February 15, 2018.

8. National Health Registry, Cause of death registry, Table of cause and manner of death, DAR01, for Eastern Denmark; 2008-2012. Available from: http://esundhed.dk/sundhedsregistre/DAR01/Sider/Tabel.aspx. Accessed October 16, 2018.
9. Pedersen AJ, Dalsgaard PW, Rode AJ, et al. Screening for illicit and medicinal drugs in whole blood using fully automated SPE and ultrahigh-performance liquid chromatography with TOF-MS with dataindependent acquisition. J Sep Sci. 2013;36(13):2081-2089.

10. Mollerup CB, Dalsgaard PW, Mardal M, Linnet K. Targeted and nontargeted drug screening in whole blood by UHPLC-TOF-MS with data-independent acquisition. Drug Test Anal. 2017;9(7):1052-1061.

11. Bjørk MK, Simonsen KW, Andersen DW, et al. Quantification of 31 illicit and medicinal drugs and metabolites in whole blood by fully automated solid-phase extraction and ultra-performance liquid chromatography-tandem mass spectrometry. Anal Bioanal Chem. 2013;405(8):2607-2617.

12. Nielsen MKK, Nedahl M, Johansen SS, Linnet K. Validation of a fully automated SPE and UHPLC-MS/MS method for quantification of 30 pharmaceuticals and metabolites in post-mortem blood and brain samples. Drug Test Analysis. 2018;10:1147-1157.

13. Simonsen KW, Steentoft A, Buck M, Hansen L, Linnet K. Screening and quantitative determination of twelve acidic and neutral pharmaceuticals in whole blood by liquid-liquid extraction and liquid chromatography-tandem mass spectrometry. J Anal Toxicol. 2010;34(7):367-373.

14. Peiris-John R, Kool B, Ameratunga S. Fatalities and hospitalisations due to acute poisoning among New Zealand adults. Intern Med J. 2014;44(3):273-281.

15. Jones AW, Holmgren A, Ahlner J. Post-mortem concentrations of drugs determined in femoral blood in single-drug fatalities compared with multi-drug poisoning deaths. Forensic Sci Int. 2016;267:96-103.

16. Medstat.dk [home page on the internet]. Pharmaceutical statistics Denmark 2008-2012. Copenhagen, Denmark: Sundhedsdata styrelsen. Available from: www.medstat.dk. Accessed October 11, 2018.

17. Roneet L, Petro S, Lee A, et al. Methadone related deaths compared to all prescription related deaths. Forensic Sci Int. 2015;257: 347-352.

18. Randall C, Crane J. Tramadol deaths in Northern Ireland: a review of cases from 1996 to 2012. J Forensic Leg Med. 2014;23:32-36.

19. Ojanperä I, Kriikku P, Vuori E. Fatal toxicity index of medicinal drugs based on a comprehensive toxicology database. Int J Legal Med. 2016;130(5):1209-1216.
Research and Reports in Forensic Medical Science

\section{Publish your work in this journal}

Research and Reports in Forensic Medical Science is an international, peer-reviewed, open access journal publishing original research, reports, reviews and commentaries on all areas of forensic medical science. The manuscript management system is completely online and includes a

\section{Dovepress}

very quick and fair peer-review system. Visit http://www.dovepress.com/ testimonials.php to read real quotes from published authors. 